\title{
Map of Earthquake Prone Areas Using Geographic Information Systems (Peta Daerah Rawan Gempa Menggunakan Sistem Informasi Geografis)
}

\author{
Rafki Imani $^{1 *}$, Heriyanto ${ }^{2}$ \\ ${ }^{1}$ Fakultas Teknik Universitas Putra Indonesia "YPTK" Padang, Sumatera Barat, Indonesia \\ ${ }^{2}$ Fakultas Ilmu Komputer Universitas Putra Indonesia "YPTK" Padang, Sumatera Barat, Indonesia \\ *E-mail: rafki_imami@upiyptk.ac.id
}

\begin{abstract}
Abstrak
Penelitian ini bertujuan untuk memetakan daerah-daerah yang rawan gempa, dan mengidentifikasi jalur alternatif terdekat untuk evakuasi korban gempa di Kecamatan Singkarak Kabupaten Solok Sumatera Barat. Metode penelitian ini dilakukan dengan metode deskriptif yang dianalisis dengan GIS (Geographic Information System) berdasarkan skala intensitas gempa (MMI). Hasil penelitian ini menyatakan bahwa 90\% desa di Kecamatan Singkarak memiliki intensitas gempa tinggi, dengan percepatan muka tanah lebih dari $0,34 \mathrm{~g}$. Untuk daerah evakuasi dapat diarahkan menjauhi daerah dengan tebing terjal dan daerah-daerah yang dekat dengan bangunan tinggi dan sebaiknya diarahkan ke arah yang dekat dengan Danau Singkarak, karena daerah di sekitar ini memiliki risiko gempa yang rendah dengan percepatan gempanya hanya $0,1 \mathrm{~g}$.
\end{abstract}

Kata kunci: Gempabumi, mitigasi, GIS

\section{Abstract [Times New Roman 10 points]}

This study aims to map the earthquake prone areas, and identify the nearest alternative route for evacuation of earthquake victims in Singkarak District, Solok Regency, West Sumatra. This research method was conducted with descriptive methods that analyzed by GIS (Geographic Information System) based on intensity scale (MMI). The results of this study stated that $90 \%$ of villages in Singkarak District had a high earthquake intensity, with an acceleration of the land surface of more than $0.34 \mathrm{~g}$. For evacuation areas can be directed away from areas with steep cliffs and areas close to high buildings and should be directed in the direction close to Lake Singkarak, because the area around this has a low earthquake risk with earthquake acceleration of only $0.1 \mathrm{~g}$.

Keywords: Earthquake, mitigation, GIS

\section{Pendahuluan}

Bencana gempabumi yang pernah melanda wilayah Kabupaten Solok pada tahun 2007 silam, telah menyebabkan jatuhnya korban meninggal dunia dan kerugian harta benda yang tidak sedikit. Salah satu daerah di kabupaten tersebut yang paling parah mengalami dampak gempa adalah Kecamatan X Koto Singkarak. Tidak seperti wilayah lainnya di Sumatera Barat (Sumbar), sebagian besar masyarakat di Kecamatan X Koto Singkarak belum banyak memahami dan mendapatkan pengetahuan mitigasi gempa secara berkelanjutan. Sosialisasi kebencanaan, khususnya bencana gempa, masih dilakukan secara terpisah dan belum terintegrasi dengan baik oleh pemangku kebijakan (stakeholders). Sementara itu masih banyaknya ditemukan warga bertahan dengan persepsi konvensional terhadap bencana alam, yang semakin mengakibatkan lemahnya kapasitas masyarakat dalam menghadapi bencana yang akan terjadi [1].

Rendahnya kapasitas masyarakat, tingkat kepanikan yang tinggi saat gempa terjadi, kurangnya kepedulian merubah persepsi konvensional tentang bencana, jumlah penduduk dan usia rentan yang tinggi serta kontur 
geografis wilayah di Kecamatan X Koto Singkarak yang sangat bervariasi, tentunya menjadi faktor penyebab utama yang berperan meningkatkan tingginya jumlah korban yang akan terdampak bencana gempa, sehingga upaya penanggulangan belum dapat berjalan secara optimal.

Permasalahan utama dari beberapa penyebab di atas adalah rendahnya kapasitas masyarakat dalam menghadapi bencana gempa. Sebagian besar masyarakat di Kecamatan X Koto Singkarak belum benar-benar mengenal dan memahami tentang sumber dan zona gempa yang sering melanda wilayahnya. Banyak yang beranggapan bahwa gempa yang selama ini terjadi adalah gempa yang bersumber di laut pada zona subduksi sebelah Mentawai. Sementara menurut para ahli kegempaan, sumber gempa yang mengancam di Sumbar, selain zona Subduksi, juga ada Sesar Sumatera yang berada di sepanjang Pulau Sumatera [2]. Akibatnya ketika gempa benar-benar terjadi, masyarakat di daerah tersebut benar-benar berada dalam kepanikan yang tinggi, dan ini tentunya menambah tingginya jumlah korban jiwa akibat terkena runtuhan bangunan.

Perubahan paradigma penanganan bencana dari tanggap darurat sampai upaya kesiapsiagaan masyarakat, menjadi perhatian pemerintah saat ini dalam upaya pengurangan risiko bencana (PRB). Berbagai upaya telah dilakukan, termasuk pengembangan sistem informasi. Salah satu program sistem informasi yang bermanfaat dalam upaya pengurangan risiko gempa adalah Sistem Informasi Geografis (Geographic Information System, GIS) [3]. Dalam penanganan kebencanaan, program GIS dapat membantu instansi terkait dalam sosialisasi dan penyuluhan kepada masyarakat [4].

Informasi lokasi dan daerah potensial gempa serta jalur terpendek yang bisa dilewati ketika mengevakuasi korban gempa, perlu dikenali dengan baik. GIS dalam hal ini mampu menyajikan informasi secara visual mengenai data-data lokasi, spasial, kependudukan dan unsur geografis, sehingga dapat memudahkan pemerintah dan instansi terkait dalam penanganan korban gempa [5]. Berdasarkan permasalahan tersebut, maka penelitian ini bertujuan untuk menyajikan peta digital daerah rawan gempa dan memberikan informasi daerah terdekat untuk jalur evakuasi gempa dengan sajian data dari GIS di Kecamatan X Koto Singkarak Kabupaten Solok Sumatera Barat.

\section{Tinjauan Literatur}

\subsection{Gempabumi}

Letak wilayah Indonesia yang berada pada kawasan ring of fire (sabuk api) dan pertemuan tiga lempeng besar dunia, menjadikan Indonesia berpotensi berbagai bencana, salah satunya adalah bencana gempabumi. Menurut Badan Meteorologi Klimatologi dan Geofisika [6], gempabumi adalah peristiwa bergetarnya bumi akibat pelepasan energi di dalam bumi secara tiba-tiba ditandai dengan patahnya lapisan batuan pada kerak bumi akibat akumulasi energi yang berasal dari pergerakan lempeng-lempeng tektonik yang dipancarkan ke segala arah berupa gelombang seismik sampai ke permukaan bumi. Jadi dapat dikatakan bahwa gempabumi adalah peristiwa getaran batuan di dasar bumi yang merambat ke permukaan berupa energi gempa [7].

\subsection{Kondisi Geologis Kecamatan X Koto Singkarak}

Kecamatan X Koto Singkarak berada di Kabupaten Solok Sumbar, dengan topografi wilayah yang bervariasi. Di bagian Utara terdapat Danau Singkarak, bagian Selatan memiliki kontur wilayah dengan dataran rendah 
yang subur, sedangkan pada bagian Barat dan Timur merupakan daratan tinggi perbukitan yang bergelombang. Luas wilayah ini mencapai 295 kilometer persegi dengan jumlah penduduk sebanyak 35.333 jiwa dengan 9485 kepala keluarga [8].

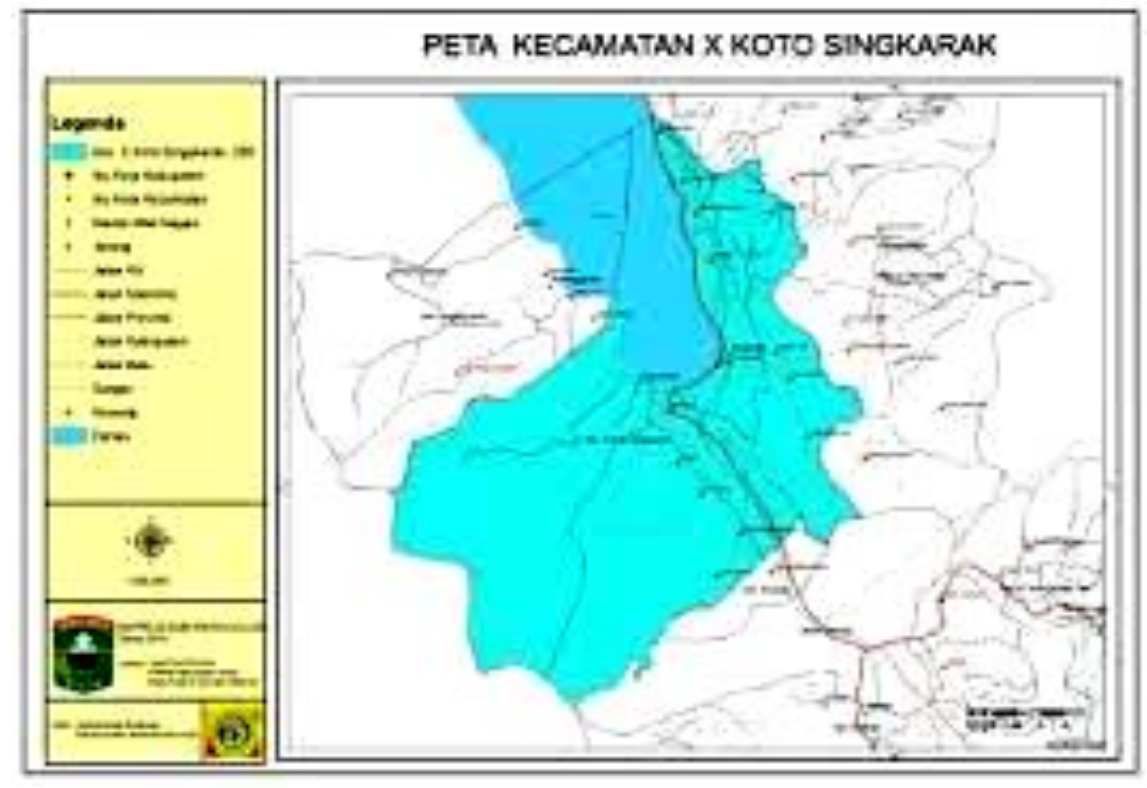

Gambar 1: Peta Kecamatan X Koto Singkarak [8].

Secara geologis wilayah di Kecamatan X Koto Singkarak dilalui oleh segmen Sesar Sumani dari rangkaian sistem Sesar Sumatera yang membujur dari Selatan Sumatera di Provinsi Lampung sampai ke Utara di Banda Aceh, yang ditandai dengan penampakan Bukit Barisan yang membelah Pulau Sumatera dengan panjang mencapai 1900 km [2]. Segmen Sesar Sumani merupakan salah satu segmen dari Sesar Sumatera yang memiliki panjang lebih kurang $60 \mathrm{~km}$ dari Danau Singkarak sampai dengan Tenggara Gunung Talang [9].

Sejarah mencatat beberapa kejadian gempa bumi kuat di segmen Sumani telah terekam dengan baik dan memiliki potensi gempa di masa mendatang. Gempa Juni 1943 di Danau Singkarak, Gempa Maret 2007 yang menyebabkan kerusakan di Kenagarian Sumani hingga Selayo, gempa di kawasan Solok pada Desember 2017 [10], serta yang terbaru gempa pada 5,5 SR yang terjadi pada 21 Juli 2018 yang menyebabkan puluhan rumah rusak berat di sekitar daerah Alahan Panjang, Nagari Simpang Tanjung Nan IV dan Lubuk Silasih Nagari Batang Barus serta satu orang meninggal dunia [11], adalah kejadian gempa di Segmen Sumani dengan jenis gempa kuat dan merusak.

\subsection{Mitigasi Gempabumi}

Undang-undang RI No. 24 tahun 2007 (UU RI No. 24/2007) menyatakan [12], ada beberapa tahapan penanggulangan bencana yang perlu dilakukan, yaitu tahap prabencana, tahap saat bencana dan tahap pascabencana (Gambar. 2). Tahap prabencana merupakan tahapan yang sangat penting dilakukan, yang meliputi segala perencanaan, penelitian, pengembangan, mitigasi, pencegahan dan kesiapsiagaan. Penanggulangan bencana alam di suatu wilayah dapat dimulai dengan mengidentifikasi kerentanan serta risiko wilayah, termasuk dengan identifikasi kerentanan penduduk, struktur bangunan dan aset penting lainnya. Gambar. 2 menjelaskan, upaya mitigasi bencana yang mungkin dilakukan adalah pemetaan daerah rawan bencana, penyiapan perangkat lunak dan penyiapan penanggulangan bencana. 


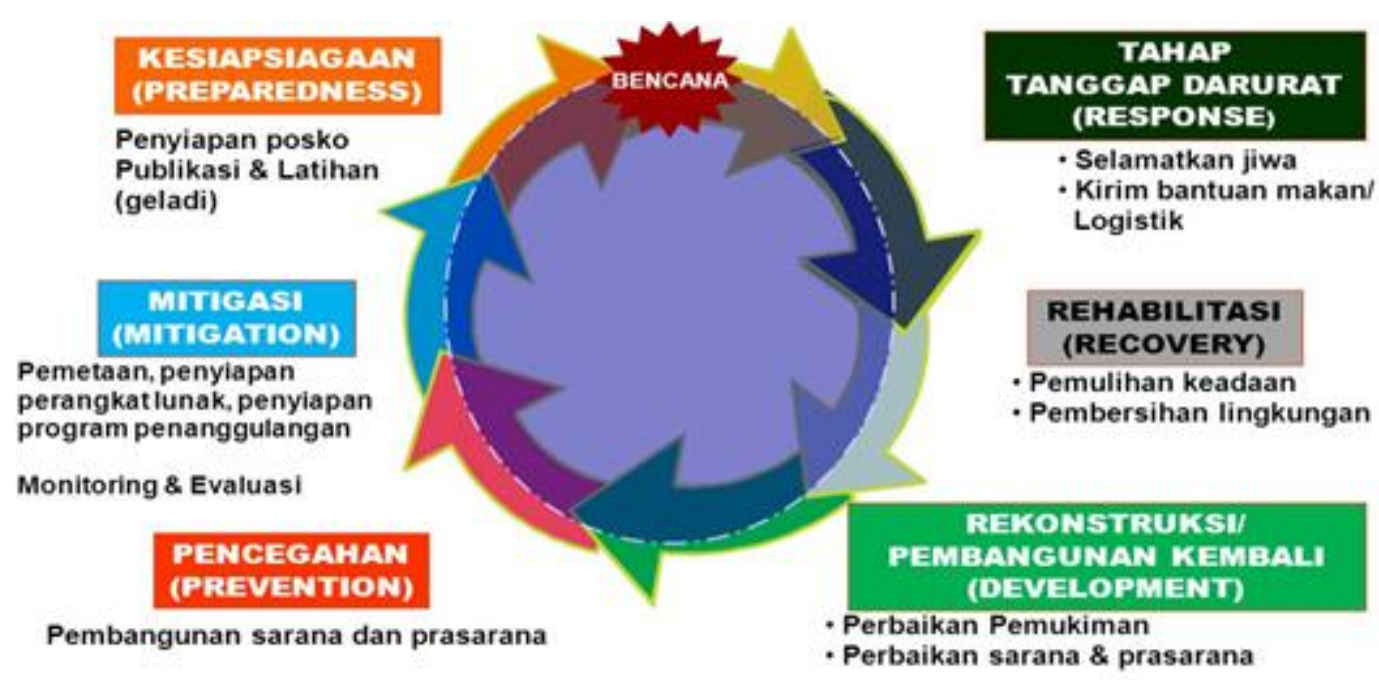

Gambar 2: Siklus manajemen bencana

Berdasarkan UU RI No. 24/2007 tersebut, mitigasi bencana merupakan serangkaian upaya yang dilakukan untuk mengurangi risiko bencana, baik melalui pembangunan fisik maupun penyadaran dan peningkatan kapasitas masyarakat untuk menghadapi ancaman bencana.

\subsection{Geographic Information System (GIS) dan Rencana Evakuasi}

Salah satu kegiatan penting dalam upaya penyadaran dan peningkatan kapasitas masyarakat dalam menghadapi bencana adalah melalui pengembangan teknologi GIS [13]. Sistem Informasi Geografis (GIS) adalah suatu alat yang dapat mendukung penetapan keputusan, salah satunya untuk membantu program pemerintah dalam penanganan kebencanaan. Menurut UU No. 24 Tahun 2007 tentang mitigasi bencana, salah satu kesiapsiagaan dalam menghadapi bencana adalah penyiapan lokasi evakuasi. Mempersiapkan jalur evakuasi korban bencana dan menyediakan informasi yang jelas tentang kebencanaan misalnya melalui peta kebencanaan, merupakan hal penting dalam mitigasi bencana.

Evakuasi korban bencana gempa harus dilakukan sesegera mungkin agar pertolongan bisa lebih tepat sasara [14]. Proses evakuasi dapat berbeda untuk masing-masing jenis bencana. Misalnya, bencana gempabumi, proses evakuasi korban dapat dilakukan dengan terlebih dahulu memindahkannya ke lokasi aman, yang jauh dari bangunan yang rentan. Rencana evakuasi bencana ini seperti yang dijelaskan pada Gambar. 3 [15]. 


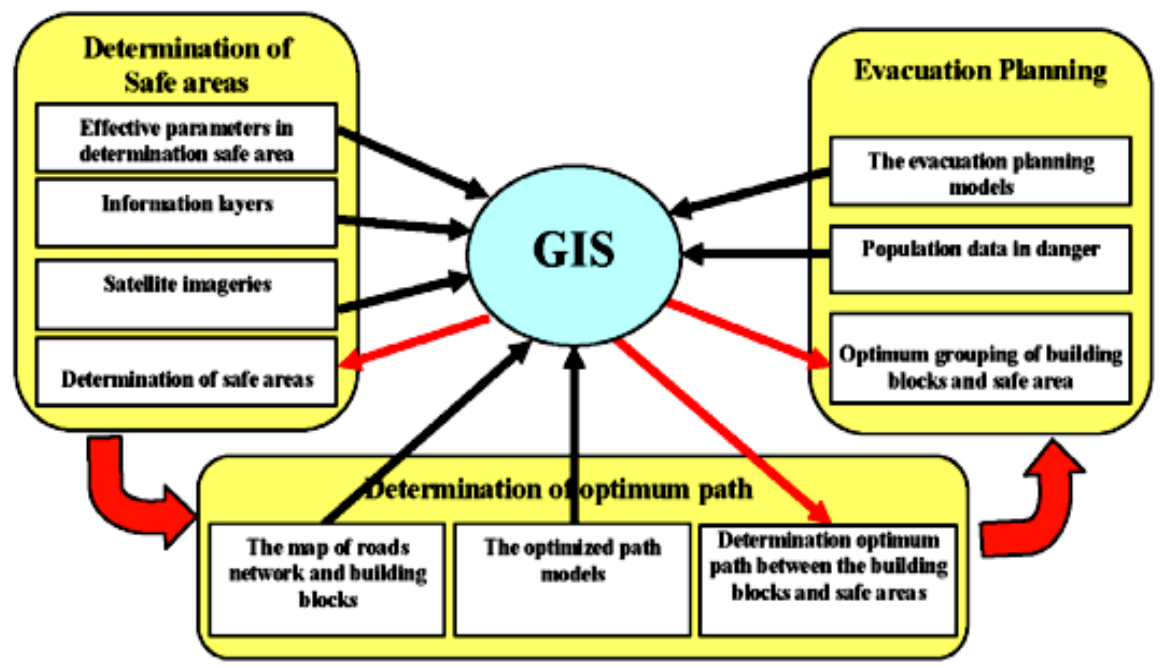

Gambar 3: Rencana evakuasi korban gempa [15].

Daerah rawan bencana dapat dipetakan dengan menggunakan GIS. Peta bencana berbasis GIS ini merupakan suatu sistem yang dapat diaplikasikan untuk memperoleh, menyimpan, menganalisa, dan mengelola data yang berkaitan dengan data secara spasial atau geografis. Menurut Ekadinata, dkk (2008) [16], GIS adalah sebuah sistem atau teknologi berbasis komputer yang dibangun dengan tujuan untuk mengumpulkan, menyimpan, mengolah, dan menganalisa, serta menyajikan data-data dan informasi dari suatu objek atau fenomena yang berkaitan dengan letak geografis wilayah atau keberadaannya di permukaan bumi.

Data geografis pada dasarnya tersusun oleh dua komponen penting yaitu data spasial dan data atribut. Data spasial merepresentasikan posisi atau lokasi geografis dari suatu objek di permukaan bumi, sedangkan data atribut memberikan deskripsi atau penjelasan suatu objek. Data atribut dapat berupa informasi numerik, foto, narasi, dan lain sebagainya, yang diperoleh dari data statistik, pengukuran lapangan dan sensus. Sumber data spasial antara lain mencakup data grafis peta analog, foto udara, citra satelit, survei lapangan dan pengukuran menggunakan Global Positioning System (GPS). Adapun format data spasial, secara umum dapat dikategorikan dalam format digital dan format analog [16].

Sistem informasi kebencanaan merupakan sebuah sistem terkomputerisasi yang digunakan dalam penanganan kebencanaan, dengan tujuan mengurangi dampak bencana. Dalam hal penanganan bencana, GIS dapat membuat pemetaan bencana yang mengandung informasi-informasi tentang wilayah yang rawan bencana. Selain itu juga menciptakan pola spasial yang mempunyai kejelasan visual. Hal ini dapat mempermudah masyarakat, khususnya pemerintah dalam memahami dan membantu mendukung proses pembuatan keputusan dalam penanganan bencana. Berikut manfaat GIS dalam bidang mitigasi bencana, adalah [17]:

1. Dapat menandai titik wilayah yang rawan bencana.

2. Dengan memetakan daerah rawan bencana melalui GIS.

3. Dapat memindai kerusakan dan luas kawasan yang terdampak bencana.

4. Dapat mengidentifikasi wilayah prioritas dalam melakukan mitigasi bencana tepat sasaran.

5. Keakuratan data dari hasil analisis GIS dapat dilakukan perencanaan yang matang untuk evakuasi korban, serta mengidentifikasi rute evakuasi alternatif.

6. Dapat digunakan untuk menentukan zona aman dalam merancang perencanaan tempat pengungsian bagi para korban.

7. Mampu memberikan perkiraan jumlah kebutuhan korban kebencanaan. 
8. Merencanakan model dan simulasi kebencanaan agar elemen yang rentan menjadi korban bencana siap secara mental ketika bencana terjadi.

9. Dapat digunakan untuk melakukan kajian kerusakan dan dampak bencana serta melakukan analisis keutuhan komunitas korban bencana.

Beberapa penelitian pemetaan wilayah bencana berbasis GIS telah banyak dikembangkan. Inopianti (2017) melakukan penelitian untuk menentukan sebaran daerah berpotensi kekeringan di Sukabumi yang dianalisis dengan GIS [18]. Dalam Wibowo, et, al., (2016), GIS digunakan untuk memetakan wilayah banjir di Kabupaten Jember Jawa Timur [19]. Putra \& Esanudin (2013) telah melakukan pemetaan daerah rawan gempa tektonik dan jalur evakuasi gempa di Yogyakarta dengan analisis GIS [20]. Kemudian Utama \& Sofyan (2010), juga telah melakukan penelitian untuk memetakan lokasi-lokasi hotel di Yogyakarta dengan hasil akhir berupa peta digital yang dihasilkan dari GIS [21]. Dalam penelitian ini, GIS digunakan untuk memetakan daerah-daerah rawan gempa berikut menginformasikan jalur evakuasi terdekat berupa peta digital di daerah Sumani Kecamatan X Koto Singkarak, Kabupaten Solok Sumbar.

\section{Metodologi}

Penelitian ini merupakan penelitian deskriptif dengan penyajian data-data kualitatif dan kuantitatif. Data kualitatif merupakan data yang diperoleh di lapangan dengan cara wawancara, observasi langsung di lapangan serta studi kepustakaan dan diolah menjadi data kuantitatif, sehingga dapat menyajikan informasi tingkat bahaya dan potensi risiko gempa yang ada di wilayah Kecamatan X Koto Singkarak Kabupaten Solok, Sumbar. Observasi lapangan dilakukan untuk mengumpulkan data-data primer serta melakukan dokumentasi dengan pengambilan foto-foto untuk memperoleh gambaran visual. Metode selanjutnya dilakukan survei ke instansi terkait untuk memperoleh data-data sekunder. Sementara proses wawancara dilakukan dengan dengan pihak-pihak terkait untuk mengetahui permasalahan-permasalahan serta hambatan yang dihadapi pada saat dan pascabencana.

Alat yang digunakan dalam studi ini adalah berupa GPS, softwere Arcview 3.2, dan didukung dengan peta topografi lembar Kecamatan X Koto Singkarak Kabupaten Solok Sumbar. Data primer yang diamati di lapangan berupa: a) kepadatan penduduk per-sektor, b) kondisi jalur evakuasi, dan c) foto jalur evakuasi. Sedangkan data sekunder yang dibutuhkan dalam studi ini berupa: a) data kependudukan, b) data statistik daerah penelitian, c) Data RT/RW, serta d) data sebaran, dimensi, kualitas dan kuantitas dari infrastruktur.

Dari hasil pengamatan dan pengambilan data di lapangan, maka dihasilkan data primer yang menjadi data dasar dalam penelitian ini. Data tersebut dianalisa untuk menentukan jalur evakuasi terdekat dan jumlah pergerakan penduduk pada tiap sektor di Kecamatan X Koto Singkarak. Data-data yang telah terkumpul kemudian diolah menjadi data GIS dijital. Untuk mengubah data menjadi data GIS dapat dilakukan dengan digitasi point, line dan poly. Hasil dari pengolahan data dalam GIS ini adalah peta dijital yang sudah dilakukan proses editing dan transformasi. Setelah data diolah kemudian dilakukan analisis data. Untuk menentukan jalur evakuasi.

\section{Hasil dan Diskusi}

Wilayah Kecamatan X Koto Singkarak, merupakan kawasan di Sumatera Barat yang cukup tinggi terdampak bencana gempa. Wilayah ini berbatasan dengan Kota Padang di sebelah Timur dengan luas daerah mencapai 295,5 km2. Risiko ancaman gempa di wilayah ini dipicu karena di lewati oleh sesar Sumani yang memanjang hingga melalui Desa Saningbakar sampai ke Desa Singkarak. 


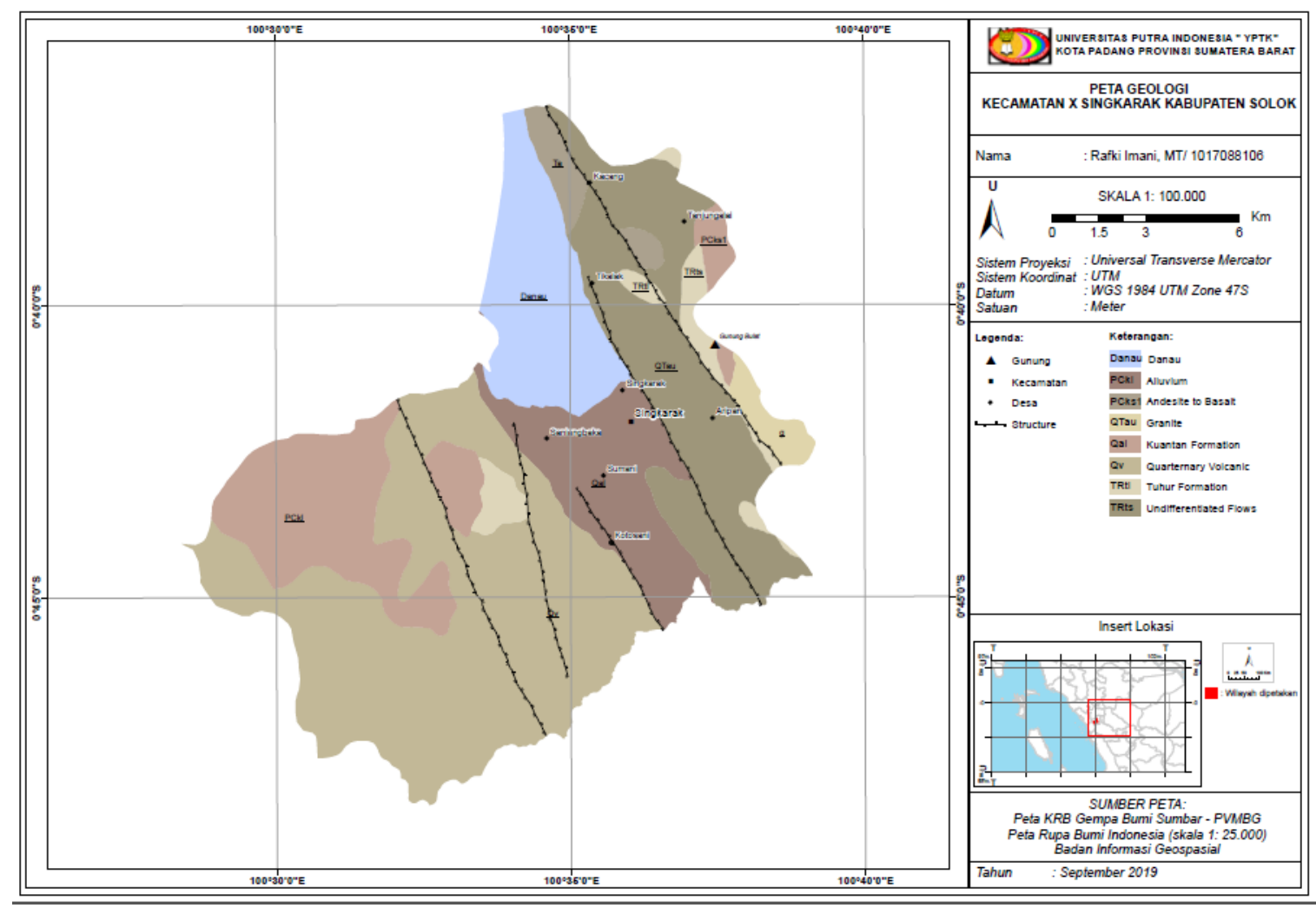

Gambar 4: Peta geologi Kecamatan X Koto Singkarak

\subsection{Metode Clustering Daerah Rawan Bencana Gempa Kecamatan X Koto Singkarak}

Peta Kawasan Rawan Bencana (KRB) gempabumi dibuat berdasarkan pembobotan terhadap empat parameter, yaitu geologi (batuan, morfologi, struktur geologi), skala intensitas MMI gempa bumi yang pernah terjadi, dan percepatan gempabumi (PGA). Berdasarkan parameter-parameter tersebut dibuat zonasi kerawanan bencana gempabumi yang termuat dalam KRB gempa Kecamatan X Singkarak Kabupaten Solok.

Zonasi tersebut yaitu di antaranya zona daerah rawan bencana gempabumi tinggi, sedang, dan rendah. Zona kerawanan gempabumi yang termuat dalam peta tersebut bersifat umum sebagai informasi awal potensi kerusakan akibat goncangan gempa bumi yang dapat melanda Kecamatan X Singkarak Kabupaten Solok.

\subsection{Daerah Rawan Bencana Gempa Tinggi}

Kawasan yang berpotensi terlanda goncangan gempabumi dengan intensitas lebih dari VIII MMI (Modefied Mercalli Intensity, MMI). Kawasan ini berpotensi terjadi retakan tanah, pelulukan, longsoran pada tebing terjal dan pergeseran tanah. Percepatan gempabumi lebih besar daripada $0.34 \mathrm{~g}$. Berdasarkan batuan, daerah ini tersusun oleh alluvium, endapan gunung api dan batuan yang telah terlapukkan secara kuat. Daerah dengan Intensitas Gempa Bumi Tinggi ini ada di hampir seluruh desa di Kecamatan X Singkarak Kabupaten Solok. 


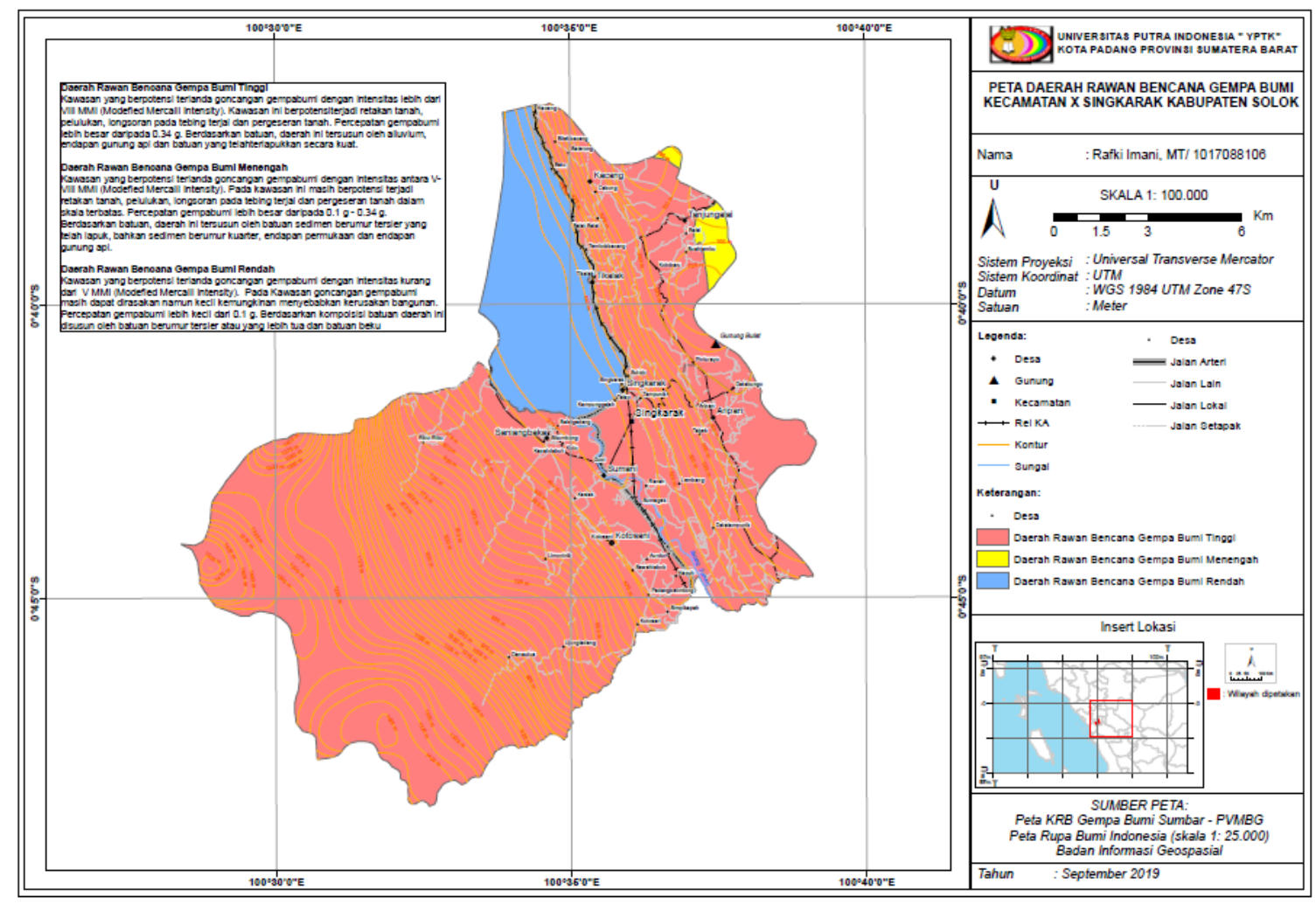

Gambar 5: Peta rawan bencana wilayah Kecamatan X Koto Singkarak Kabupaten Solok, Sumbar

\subsection{Daerah Rawan Bencana Gempa Sedang}

Kawasan yang berpotensi terlanda goncangan gempabumi dengan intensitas antara V-VIII MMI (Modefied Mercalli Intensity). Pada kawasan ini masih berpotensi terjadi retakan tanah, pelulukan, longsoran pada tebing terjal dan pergeseran tanah dalam skala terbatas. Percepatan gempabumi lebih besar daripada $0.1 \mathrm{~g}-$ $0.34 \mathrm{~g}$. Berdasarkan batuan, daerah ini tersusun oleh batuan sedimen berumur tersier yang telah lapuk, bahkan sedimen berumur kuarter, endapan permukaan dan endapan gunung api. Daerah dengan Intensitas Gempa Menengah ini berada di sebagian wilayah Desa Tanjungalai tepatnya di daerah Balai dan Buah Jambu.

\subsection{Daerah Rawan Bencana Gempa Rendah}

Kawasan yang berpotensi terlanda goncangan gempabumi dengan intensitas kurang dari V MMI. Pada Kawasan goncangan gempabumi masih dapat dirasakan namun kecil kemungkinan menyebabkan kerusakan bangunan. Percepatan gempabumi lebih kecil dari 0,1 g. Berdasarkan kompoisisi batuan daerah ini disusun oleh batuan berumur tersier atau yang lebih tua dan batuan beku. Daerah dengan Intensitas Gempa Bumi Rendah ini ada di daerah kawasan Danau Singkarak di Kecamatan X Singkarak Kabupaten Solok. Untuk arah evakuasi adalah dimana menghindari daerah dengan tebing terjal dan daerah dengan banyak bangunanbangunan tinggi. Untuk daerah terbaik evakuasi adalah di kawasan Danau Singkarak.

\section{Kesimpulan}

Beberapa kesimpulan yang dapat ditarik adalah:

a. Hampir sebagian besar desa yang ada di Kecamatan X Koto Singkarak memiliki intensitas gempa tinggi. 
b. Desa dengan intensitas gempa sedang adalah Desa Tanjuang Alai.

c. Desa dengan intensitas gempa rendah adalah desa-desa yang ada di dekat Danau Singkarak.

d. Arah evakuasi diarahkan ke kawasan yang dekat dengan Danau Singkarak.

\section{Referensi}

[1] H. Agustin, "Persepsi Masyarakat Kenagarian Sumani Tentang Kesiapsiagaan Bencana Gempa Bumi (Perception of the society of Sumani Village about Disaster Preparedness)," Jurnal Kesehatan Komunitas, 2(5), 199-206, 2014.

[2] D. H Natawidjaja, "Gempa Bumi dan Tsunami di Sumatra dan Upaya Untuk Mengembangkan Lingkungan Hidup Yang Aman Dari Bencana Alam," Portal Geospasial, Kementerian Lingkungan Hidup, 1-3 (December), 66, 2007.

[3] H. Nakai, T. Itatani, R. Horiike, K. Kyota, K. Tsukasaki, "Tsunami evacuation simulation using geographic information systems for homecare recipients depending on electric devices," PLoS ONE, 13(6), 1-10. https://doi.org/10.1371/journal.pone.0199252, 2018.

[4] Y. Yuhendra, A. N. D. Syafrudin, "Sistem Informasi Geografis Pemetaan Jalur Evakuasi Tsunami Berbasis Web (Studi Kasus : Kecamatan Tanjung Mutiara Kabupaten Agam)," Peranan Ipteks Menuju Industri Masa Depan (PIMIMD-4), 91-96, 2017.

[5] D. M. Putra, R. Esanudin, "Review Jurnal Sistem Informasi Geografis Untuk Pemetaan Daerah Rawan Gempa Tektonik Dan Jalur Evakuasi di Yogyakarta," UNIVERSITAS SEBELAS MARET TAHUN AKADEMIK 2013. Jurnal Penelitian IPTEK-KOM, 14, 1-7, 2013.

[6] BMKG, "Katalog Gempabumi Signifikan dan Merusak 1821 - 2017," Jakarta: Pusat Gempabumi dan Tsunami Badan Meteorologi Klimatologi dan Geofisika, 2018.

[7] R. Imani, U. D. Arman, W. Boy, "Correlation between type of ground-based on b-value and the impact on buildings due to Sumatra earthquakes," MATEC Web of Conferences, 02013(229), 2018.

[8] BPS Kabupaten Solok, "Badan Pusat Statistik Kabupaten Solok. Kabupaten Solok: Pemerintah Daerah Kabupaten Solok,” 2018.

[9] Z. Netrisa, Syafriani, R. Triyono, H. Arifin, "Pemetaan Bahaya Gempabumi Deterministik dengan Pendekatan Peak Ground Acceleration ( PGA ) di Kota Padang," Pillar of Physics, 11(2), 41-48, 2018.

[10] BPBD Sumbar, "Peta Bahaya Gempa Bumi Zona Patahan Provinsi Sumatera,” 2019.

[11] BNPB, “Laporan Kinerja Tahun 2018. Badan Nasional Penanggulangan Bencana,” 2018.

[12] Undang-undang Republik Indonesia Nomor 24 Tahun 2007 Tentang Kebencanaan, 2007.

[13] A. Mustofa, A. Rosidi, A. Sofyan, "Analisis Sistem Informasi Geografis Untuk Bencana Gempa Bumi Terintegrasi Di Daerah Istimewa Yogyakarta. Data Manajemen dan Teknologi Informasi (DASI)," 16(2), 19, 2015.

[14] A. Rezki, "Aplikasi Sistem Informasi Geografis (SIG) untuk Analisis Akses Terdekat dan Jumlah Pergerakan Penduduk Melewati Jalur Evakuasi di Kota Padang," Jurnal Spasial Program Studi Pendidikan Geografi STKIP PGRI Sumatera Barat, 40-54, 2015. 
[15] K. Naghdi, A. Mansourian, M. J. Valadanzoej, M. Saadatseresht, "Evacuation planning in earthquake disasters, using RS \& GIS. The International Archives of the Photogrammetry, Remote Sensing and Spatial Information Sciences,” XXXVII (January), 1671-1676, 2008.

[16] A. Ekadinata, S. Dewi, D. P. Hadi, D. K. Nugroho, F. Johana, "Sistem Informasi Geografis Untuk Pengelolaan Bentang Lahan Berbasis Sumber Daya Alam." Bogor: World Agoforestry Centre ICRAF South East Asia Regional Office, 2008.

[17] Mariopiss, "Pemanfaatan SIG (System Information Geografis) Untuk Mitigasi Bencana," Diambil dari http://mariopiss.wordpress.com/2017/04/13/pemanfaatan-sig-system-information-geografis-untukmitigasi-bencana/, 2018.

[18] N. Inopianti, "Pemanfaatan aplikasi sistem informasi geografis (sig) dan penginderaan jauh untuk pemetaan daerah rawan kekeringan di kabupaten sukabumi," Universitas Islam Negeri Syarif Hidayatullah Jakarta, 2017.

[19] R. Imani, U. D. Arman, W. Boy, "Correlation between type of ground-based on b-value and the impact on buildings due to Sumatra earthquakes," MATEC Web of Conferences, 02013(229), 2018.

[20] D. M. Putra, R. Esanudin, "Review Jurnal Sistem Informasi Geografis Untuk Pemetaan Daerah Rawan Gempa Tektonik Dan Jalur Evakuasi di Yogyakarta, "UNIVERSITAS SEBELAS MARET TAHUN AKADEMIK 2013. Jurnal Penelitian IPTEK-KOM, 14, 1-7, 2013.

[21] P. K. L. Utama, A. F. Sofyan, "Perancangan dan Implementasi Sistem Informasi Geografis Lokasi Hotel di Yogyakarta Menggunakan SVG," Jurnal Dasi, 11(1), 1-11, 2010. 